\title{
An Assessment of the Compliance and Utility of a Home Exercise DVD for Caregivers of Children and Adolescents With Brachial Plexus Palsy: A Pilot Study
}

\author{
Kathleen M. Murphy, BSE, Lynnette Rasmussen, OTRL, Shawn L. Hervey-Jumper, MD, \\ Denise Justice, OTRL, Virginia S. Nelson, MD, MPH, Lynda J.-S. Yang, MD, PhD
}

Objective: To investigate the impact of a video-based educational resource on home exercise compliance among caregivers of children with neonatal brachial plexus palsy (NBPP).

Design: Retrospective analysis of self-reported caregiver home exercise habits and resultant shoulder range of motion (ROM) and biceps power in patients with NBPP.

Setting: Home-based exercise program.

Participants: Adult caregivers of children with NBPP followed up through the Brachial Plexus Program at the University of Michigan $(\mathrm{N}=83$ surveyed initially, with $\mathrm{N}=37$ completing the final survey).

Methods: Caregivers completed surveys before and approximately 3, 6, and 12 months (times A, B, and C, respectively) after receiving the "Home Exercise Therapy Program for Brachial Plexus Palsy" digital video disk (DVD). A retrospective analysis of shoulder ROM and biceps power of patients was completed as representative of arm function during the study.

Main Outcome Measurements: Surveys assessed home exercise compliance, resources used to guide exercises, and caregiver confidence in the correctness of exercises being performed. Functional outcomes analyzed include biceps strength and shoulder active and passive ROM.

Results: Home exercise compliance increased from $74 \%$ initially to $96 \%$ at time A ( $P<$ $.001)$, remained at $94 \%$ at time B $(P<.001)$, and fell to $84 \%$ at time $C(P=.016)$. Use of the DVD to guide home exercise decreased from $69 \%$ at time A to $57 \%$ at time B and C ( $P=$ .026). After receiving the DVD, exercise frequency and caregiver confidence increased. Although some measures of shoulder active ROM and biceps power improved during the course of the study, there was no consistent statistically significant relationship between increased caregiver confidence and functional outcomes. No causal relationship exists between DVD content and functional status at this time.

Conclusions: As the first formal evaluation of a video-based resource guiding exercise therapy for children with NBPP, we suggest that this population may be receptive to alternative media and may benefit from dynamic modeling of home exercises.

PM R 2012;4:190-197

\section{INTRODUCTION}

Neonatal brachial plexus palsy (NBPP) affects approximately 1.5 of 1000 live births [1], resulting from nerve injury attributed to compression, traction, or inflammation of the brachial plexus, either in utero or during the perinatal period [2]. Although the majority of infants with NBPP recover with conservative management, 10\%-30\% require more aggressive treatment, which may include surgical nerve repair or brachial plexus reconstruction $[2,3]$. Exercise therapy remains an essential component of treatment for all patients with NBPP [2,4] to maintain range of motion (ROM) and muscle strength, and to prevent contractures and joint deformities in the children's affected arm [5,6].

Caregivers of patients with NBPP are often shown exercises by professional therapists and then asked to continue performing these exercises at home [4]. Research on therapy
K.M.M. Department of Physical Medicine and Rehabilitation, University of Michigan Medical School, Ann Arbor, MI

Disclosure: nothing to disclose

L.R. Department of Neurosurgery, University of Michigan Medical School, Ann Arbor, Ml Disclosure: nothing to disclose

S.L.H-J. Department of Neurosurgery, University of Michigan Medical School, Ann Arbor, M Disclosure: nothing to disclose

D.J. Department of Neurosurgery, University of Michigan Medical School, Ann Arbor, MI Disclosure: nothing to disclose

V.S.N. Department of Physical Medicine and Rehabilitation, University of Michigan Medical School, Ann Arbor, Ml Disclosure: nothing to disclose

L.J.-S.Y. Department of Neurosurgery, University of Michigan Health System, 1500 E Medical Center Drive, Room 3552 Taubman Center, Ann Arbor, Ml 48109-5338. Address correspondence to: L.J.-S.Y.; e-mail: ljsyang@ med.umich.edu

Disclosures: 1B, member of the Board of Directors, Sparton Corp; 2B, FDA.

Disclosure Key can be found on the Table of Contents and at www.pmrjournal.org

Submitted for publication March 15, 2011 ; accepted August 29, 2011 
Table 1. Home exercise DVD recipient demographics

\begin{tabular}{|c|c|c|c|c|}
\hline & Initial Survey & Time A & Time B & Time C \\
\hline No. caregivers surveyed & 83 & 72 & 62 & 37 \\
\hline Time of follow-up survey (mo) & & $3.6 \pm 3.2$ & $8.0 \pm 3.6$ & $12.5 \pm 4.2$ \\
\hline Median (SD) Narakas score of the child & $2 \pm 0.8$ & $2 \pm 0.9$ & $2 \pm 0.9$ & $2 \pm 0.9$ \\
\hline $0-12 \mathrm{mo}$ & 35 (42\%) & $31(43 \%)$ & $28(45 \%)$ & $16(43 \%)$ \\
\hline $1-4$ y & $25(30 \%)$ & $22(31 \%)$ & $17(27 \%)$ & $12(32 \%)$ \\
\hline $5-10 y$ & $18(22 \%)$ & $16(22 \%)$ & $14(23 \%)$ & $8(22 \%)$ \\
\hline $\begin{array}{l}\text { Mean difference in child's age when the DVD was received } \\
\text { compared with the initial survey (mo) }\end{array}$ & & $2.98 \pm 7.3$ & $2.57 \pm 7.8$ & $4.80 \pm 9.1$ \\
\hline
\end{tabular}

instruments for home exercise programs, exercise compliance, and the impact of these instruments on arm function has been scarce. Similar home exercise programs have been used for children with cerebral palsy who also face movement challenges $[7,8]$. Factors that influence compliance in patients with cerebral palsy include caregiver participation, complexity of exercises, personal motivation, and family lifestyle $[7,8]$. Studies of children with motor disabilities show that up to $50 \%$ of caregivers do not comply with a recommended home exercise program $[9,10]$. Because the efficacy of an exercise program depends on the accurate performance of exercises, the motivation and proper instruction of caregivers are critical [11].

In an increasingly multimedia-driven society, the development of new technologies has influenced how health professionals share information with patients. Recent studies examined the use of videos, video games, and CD-ROM programs as tools to enhance patient education and improve treatment compliance [12-16]. Video-based resources have low incremental cost, can be used by patients with limited literacy, and can promote patient empowerment [14]. Video-based patient education has been found to facilitate short-term knowledge acquisition and to encourage therapeutic behaviors in diverse patient populations [12,14-17]. To date, to our knowledge, no published studies have examined the impact of multimedia resources on patient education in the NBPP population.

We examined compliance with a home exercise program among caregivers of children with NBPP, and the effect that receiving a digital video disk (DVD) with dynamic exercise modeling has on caregiver compliance, confidence, and frequency and duration of exercises performed. As indicators of arm function in patients with NBPP, we compared shoulder ROM and biceps power at the time that the caregivers initially received the DVD to measurements taken at subsequent follow-up appointments.

\section{METHODS}

\section{Participants}

Participants included adult caregivers of children evaluated in the Brachial Plexus Program for treatment of NBPP. Over a 12-month period, written consent was obtained from 85 caregivers during clinic visits. Caregivers whose children were filmed on the DVD or who were non-English speaking were excluded from the study. Caregivers of 2 children whose brachial plexus injuries stemmed from childhood trauma were later removed from the study, which left 83 initial survey responses for analysis. After completing the initial survey, the caregivers received the "Home Exercise Therapy Program for Brachial Plexus Palsy" DVD (2008 Fred P. Sage Multimedia Award, AACPDM Annual Meeting, Atlanta, GA), and a recommendation of exercise frequency. All the families had access to their own DVD players. On the DVD, therapists model exercise routines aimed to increase arm strength and flexibility. The institutional review board at our institution approved the research protocol.

\section{Data Collection}

Caregivers completed an initial survey before receiving the DVD, and completed the same survey at their child's 3-, 6-, and 12-month follow-up appointments. Follow-up times are referred to as time A (median, $3.6 \pm 3.2$ months), time B (median, $8 \pm 3.6$ months), and time $\mathrm{C}$ (median, $12.5 \pm 4.2$ months) (Table 1). Of the 83 caregivers initially surveyed, 72 (87\%) were evaluated at time A, 62 (75\%) were evaluated at both times A and B, and 37 (45\%) were followed up through times $\mathrm{A}, \mathrm{B}$, and $\mathrm{C}$. The reasons for caregivers being lost to follow-up included family relocation, resolution of NBPP, missed appointments, and an inability to contact caregivers. Demographic data recorded for caregivers included their child's median Narakas score (which indicated the severity of NBPP) and age at the initial survey.

Arm functional measurements for the children of the caregivers were obtained from a data set collected during regularly scheduled clinic visits. Measurements of biceps power and shoulder passive and active ROM were compared between the times of the initial and follow-up surveys. All measurements were obtained by 2 occupational therapists who were trained in the assessment and recording of these measurements (D.J., L.R.). No interrater reliability data were collected. 


\section{Survey Measures}

Survey questions asked caregivers about weekly therapy attendance and home exercise compliance (Appendix A). The caregivers indicated resources that they used to guide home exercise: the program's DVD, a written handout, memory, or instructions from a class or other source not listed. The caregivers rated their confidence in the correctness of the exercises performed by using a 5-point visual analog scale scored as 0 (no confidence), 1 (not very confident), 2 (partly confident), 3 (fairly confident), and 4 (very confident). Exercise frequency was scored as the following: 1 (daily), 2 (weekly), 3 (monthly), and 4 (not at all). Exercise duration was scored as the following: 1 (less than 10 minutes), 2 (between 10 and 20 minutes), and 3 (more than 20 minutes).

\section{Arm Function Measures}

Arm function was analyzed via a retrospective review of measurements recorded by 2 occupational therapists (D.J., L.R.) during clinic visits and stored in an institutional review board-approved database. Arm function indicators included shoulder passive and active ROM (abduction and external rotation in abduction and adduction) and biceps motor strength by manual muscle testing graded on the British Medical Research Council (MRC) scale: 0 (not testable) to 5 (normal strength) [18].

\section{Statistical Analysis}

Independent sample $t$-tests were performed by using SPSS version 18.0 software (SPSS Inc, Chicago, IL) to compare the mean age of children of caregivers initially surveyed and followed up through each time point. Two-sampled, 2-tailed tests of proportions (SPSS) were used to determine differences in the percentages of caregivers attending weekly therapy sessions and following a home exercise program at each time point, as well as differences in the resources that caregivers were using to guide home exercises after receiving the DVD. Nonparametric analysis (SAS version 9.2, SAS Institute, Cary, NC) was performed to compare differences in the mean confidence rating of caregivers and the frequency and duration of exercise at each time point. Paired sample $t$-tests (SPSS) were used to compare shoulder ROM measurements and biceps strength at each time point.

Chi-square tests were applied to evaluate whether a causal relationship existed between caregiver confidence and functional outcomes. We categorized caregivers with a confidence level of 3 or greater as confident, and caregivers with a confidence level of less than 3 as nonconfident. For muscle strength, any patients who reached MRC grade 3 or 4 were categorized as functional; any patients with MRC less than grade 3 or 4 were categorized as nonfunctional. For active ROM, shoulder abduction greater than $90^{\circ}$ was classified as functional, and shoulder external rotation in abduction- adduction greater than $0^{\circ}$ was functional. For passive ROM, shoulder abduction greater than $170^{\circ}$ was functional, and shoulder external rotation in abduction-adduction greater than $70^{\circ}$ was functional. To examine the change in confidence level and functional outcomes at each time point, we also calculated odds ratios through logistic regressions. with functional-nonfunctional categorized outcomes (for muscle strength, active ROM [AROM] , and passive ROM [PROM]) as dependent variables.

\section{RESULTS}

\section{Demographics}

Eighty-three caregivers completed the initial survey and received the DVD. Their children had a mean age \pm standard deviation (SD) of $40 \pm 47.7$ months (range, 0-207 months) when the DVD was received, and a median Narakas score \pm SD of $2 \pm 0.830$. The caregivers completed follow-up surveys at the various time points as follows: $72(87 \%)$ at time A; $62(75 \%)$ at times A and B; and 37 (45\%) at times A, B, and C. The mean age and Narakas score of each child upon receipt of the DVD did not vary significantly among study participants at follow-up time points $(P>.5)$ (Table 1).

\section{Weekly Therapy Participation}

The percentage of caregivers reporting participation in formal weekly therapy at a facility outside the home did not significantly change from initial survey (49\%) to time A $(44 \% ; P=.40)$, time B $(45 \% ; P=.51)$, or time C $(41 \%$; $P=.28)$.

\section{Home Exercise Program Compliance}

The percentage of caregivers performing home exercise with their child increased from initial survey $(74 \%)$ to time A (96\%; $P<.001)$, remained higher through time B (94\%; $P<$ $.001)$, and decreased to $84 \%$ at time C $(P=.016)$.

\section{Resources Used to Guide Home Exercise Program}

At time A, $69 \%$ of caregivers surveyed reported using the DVD to guide home exercise (Figure 1). Use of the DVD dropped at time B to $57 \%(P=.026)$ and remained at $57 \%$ at time $\mathrm{C}$. The percentage of caregivers who used the written handout decreased from the initial survey $(42 \%)$ to time A $(29 \% ; P=.026)$ and remained lower at time B $(19 \% ; P<$ $.001)$ and time $C(19 \% ; P=.004)$. The percentage of caregivers who used memory to guide home exercise increased from the initial survey (45\%) to time A (64\%; P < $.001)$, and remained higher at time B $(63 \% ; P=.004)$ and time $C(70 \%, P=.002)$. The percentage of caregivers who used a class or "other" to guide home exercise did not 


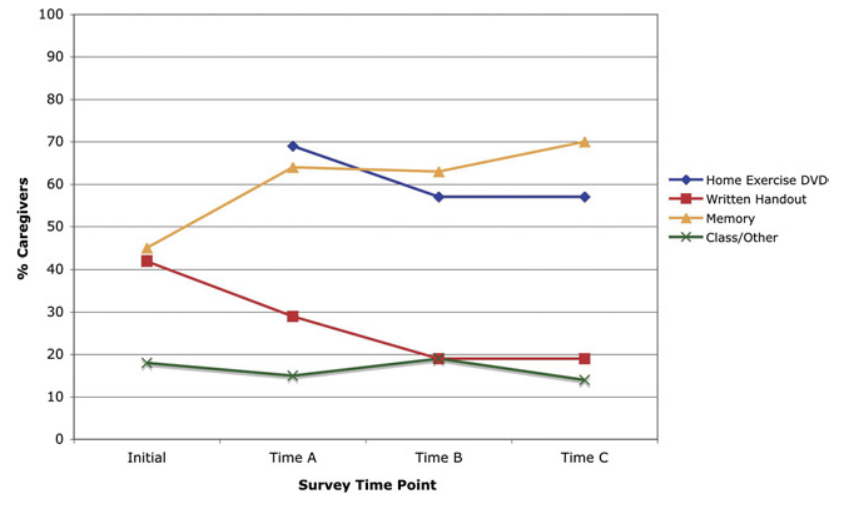

Figure 1. Line graph comparison of resources used to guide a home exercise program, as reported by patient caregivers at various time points.

significantly change from the initial survey (18\%) to follow-up appointments.

\section{Caregiver Confidence, and Frequency and Duration of Exercise}

There was a small but significant increase in caregiver confidence in the correctness of the exercises being performed, from fairly confident (3.0) at the initial survey toward very confident at time $\mathrm{A}(3.5 ; \mathrm{P}=.012)$, time $\mathrm{B}(3.5 ; \mathrm{P}<.001)$, and time $\mathrm{C}(3.5 ; P=.011)$. A small but significant increase in exercise frequency was observed from 1-5 times weekly (2.0) at the initial survey toward 1-7 times daily at time A (1.5; $\mathrm{P}=$ .0057), but no significant change occurred at time B or C. There was no significant change in the exercise duration (Table 2).

\section{Arm Function With Home Exercise DVD Use}

Shoulder passive and active ROM measurements from children whose caregivers participated in the study were avail- able for $78 \%(n=65$, passive $)$ and $67 \%(n=56$, active $)$ of children at the time of the initial survey, 59\% ( $n=49$, passive) and $57 \%$ ( $n=47$, active) of children at time A, $52 \%$ ( $\mathrm{n}=43$, passive) and $47 \%(\mathrm{n}=39$, active $)$ at time $\mathrm{B}$, and $30 \%(\mathrm{n}=25$, passive $)$ and $27 \%(\mathrm{n}=22$, active $)$ of children at time C (Table 3).

Shoulder passive ROM measurements did not change significantly from initial survey to follow-up appointments (Table 3). Active shoulder ROM in abduction increased significantly from initial survey to time A (mean SD increase, $21^{\circ} \pm 7^{\circ} ; P=.006$ ), time $\mathrm{B}$ (mean increase, $34^{\circ} \pm 9^{\circ} ; P=$ .001 ), and time $\mathrm{C}$ (mean increase, $40^{\circ} \pm 16^{\circ} ; P=.02$ ). Active shoulder external rotation in adduction did not significantly change from the initial survey to follow-up appointments. Active shoulder external rotation in abduction increased from the initial survey to time A (mean increase, $12^{\circ} \pm 34^{\circ}$; $P=.025)$ and time $\mathrm{B}$ (mean increase, $20^{\circ} \pm 52^{\circ} ; \mathrm{P}=.032$ ) (Table 3).

Biceps power measurements were available for $77 \%(\mathrm{n}=$ 64) of children at the time of the initial survey, $59 \%(n=49)$ of children at time A, $52 \%(n=43)$ of children at time B, and $30 \%(n=25)$ of children at time C (Table 3$)$. Biceps power increased from the initial survey to time A (mean SD increase, $0.6 \pm 0.9 ; P<.001$ ), time B (mean increase, $0.9 \pm 1.2 ; P<$ .001 , and time $C$ (mean increase, $1.1 \pm 1.4 ; P=.001$ ).

The $\chi^{2}$ tests only showed statistically significant relationships between "confident" caregivers and "functional" arm motion outcomes for biceps strength at time B $(P=.01)$, active shoulder abduction at the initial survey $(P=.05)$, and passive external rotation in abduction at times $\mathrm{A}$ and $\mathrm{B}(\mathrm{P}=$ .01). No odds ratios calculated from the logistic regression model reached statistical significance to show an increased likelihood of children with confident parents achieving functional ROM or biceps strength outcomes.

\section{DISCUSSION}

Educating caregivers of children with NBPP about the importance of home exercise and correct exercise technique has

Table 2. Caregiver confidence and exercise frequency, and duration at various time points related to receipt of the home exercise DVD

\begin{tabular}{|c|c|c|c|c|}
\hline & Initial Survey & Time A & Time B & Time C \\
\hline $\begin{array}{l}\text { Mean (SD) confidence rating ( } 0, \text { no } \\
\text { confidence; } 1 \text {, not very } \\
\text { confident; } 2 \text { sort of confident; } 3 \text {, } \\
\text { fairly confident; } 4 \text {, very confident) }\end{array}$ & $3.0 \pm 0.2(n=76)$ & $3.5 \pm 0.1(n=69)$ & $3.5 \pm 0.1(n=62)$ & $3.5 \pm 0.1(n=36)$ \\
\hline$P$ value & $<.0001$ & .01 & .0009 & .01 \\
\hline $\begin{array}{l}\text { Mean (SD) frequency of exercises (1, } \\
\text { 1-7 times daily; } 2,1-5 \text { times } \\
\text { weekly; } 3,1-3 \text { times monthly; } 4 \\
\text { not at all) }\end{array}$ & $2.0 \pm 0.1(n=77)$ & $1.5 \pm 0.1(n=71)$ & $1.5 \pm 0.1(n=61)$ & $1.5 \pm 0.2(n=35)$ \\
\hline$P$ value & $<.0001$ & .006 & .08 & .57 \\
\hline $\begin{array}{l}\text { Mean (SD) duration of exercises (1, } \\
\quad<10 \mathrm{~min} ; 2,10-20 \mathrm{~min} ; 3,>20 \mathrm{~min})\end{array}$ & $1.5 \pm 0.1(n=68)$ & $1.5 \pm 0.1(n=70)$ & $1.6 \pm 0.1(n=59)$ & $1.5 \pm 0.1(n=32)$ \\
\hline$P$ value & $<.0001$ & .87 & .91 & .46 \\
\hline
\end{tabular}


Table 3. Functional measure analyses performed at various time points after receipt of home exercise DVD

\begin{tabular}{|c|c|c|c|c|c|c|c|}
\hline & \multicolumn{4}{|c|}{ Shoulder Range of Motion and Motor Strength } & \multicolumn{3}{|c|}{ Functional Measures Paired Sample t-Test } \\
\hline $\begin{array}{l}\text { External rotation in abduction, } \\
\text { passive (degrees) }\end{array}$ & $(n=65)$ & $82 \pm 28(n=49)$ & $15(n=43)$ & $78 \pm 24(n=25)$ & $\begin{array}{r}-0.8 \pm 19 \\
\quad P=.\end{array}$ & $\begin{array}{l}=43) \\
91)\end{array}$ & $\begin{array}{r}-3 \pm 1 \\
\quad(P=\end{array}$ \\
\hline $\begin{array}{l}\text { External rotation in abduction, } \\
\text { active (degrees) }\end{array}$ & $4 \pm 66(n=56)$ & $12 \pm 69(n=47)$ & $16 \pm 64(n=39)$ & $4 \pm 58(n=22)$ & $\begin{array}{l}12 \pm 34(n=41) \\
\quad(P=.025)\end{array}$ & $\begin{array}{c}20 \pm 52(n=34) \\
(P=.032)\end{array}$ & $\begin{array}{c}20 \pm 65(n=19) \\
(P=.205)\end{array}$ \\
\hline $\begin{array}{l}\text { External rotation in adduction, } \\
\text { passive (degrees) }\end{array}$ & $69 \pm 27(n=65)$ & $72 \pm 26(n=49)$ & $69 \pm 29(n=43)$ & $66 \pm 28(n=28)$ & $\begin{array}{l}-1 \pm 23(n=49) \\
\quad(P=.756)\end{array}$ & $\begin{array}{c}0 \pm 23(n=43) \\
(P=1.00)\end{array}$ & $\begin{array}{c}-6 \pm 23(n=25) \\
\quad(P=.206)\end{array}$ \\
\hline $\begin{array}{l}\text { Shoulder abduction, passive } \\
\text { (degrees) }\end{array}$ & $170 \pm 20(n=65)$ & $176 \pm 10(n=49)$ & $172 \pm 18(n=43)$ & $167 \pm 22(n=25)$ & $\begin{array}{l}6 \pm 23(n=49) \\
(P=.097)\end{array}$ & $\begin{array}{c}2 \pm 25(n=43) \\
(P=.530)\end{array}$ & $\begin{array}{c}-1 \pm 32(\mathrm{n}=25) \\
(P=.850)\end{array}$ \\
\hline $\begin{array}{l}\text { Shoulder abduction, active } \\
\text { (degrees) }\end{array}$ & $78 \pm 63(n=56)$ & $94 \pm 61(n=47)$ & $97 \pm 57(n=40)$ & $90 \pm 55(n=22)$ & $\begin{array}{c}21 \pm 7(n=41) \\
(P=.006)\end{array}$ & $\begin{array}{c}34 \pm 9(n=35) \\
(P=.001)\end{array}$ & $\begin{array}{c}40 \pm 16(n=19) \\
(P=.020)\end{array}$ \\
\hline $\begin{array}{l}\text { Biceps strength (British MRC } \\
\text { grade 0-5) }\end{array}$ & $2 \pm 1.5(n=65)$ & $3 \pm 1.3(n=49)$ & $3 \pm 1.2(n=43)$ & $3 \pm 1.2(n=24)$ & $\begin{array}{l}0.6 \pm 0.9(n=49) \\
\quad(P<.001)\end{array}$ & $\begin{array}{c}0.9 \pm 1.2(n=43) \\
(P<.001)\end{array}$ & $\begin{array}{c}1.1 \pm 1.4(\mathrm{n}=24) \\
(P=.001)\end{array}$ \\
\hline
\end{tabular}

MRC $=$ Medical Research Council.

traditionally been accomplished by physicians and therapists through face-to-face demonstration, verbal instruction, and written handouts with illustrations. However, written exercise instruction may not increase the ability of patients to reproduce exercises from memory and does not promote correctness of exercise technique as effectively as dynamic modeling by therapists $[19,20]$. Studies that compared video and static-photograph exercise instruction found that video instruction encouraged greater accuracy of movements and confidence in correctness of exercises, and increased motivation to exercise $[21,22]$.

Because exercises taught to caregivers of children with NBPP can be difficult to perform at home away from therapist demonstration, video instruction with dynamic modeling of exercises may benefit patients with NBPP. Our DVD guides caregivers through a follow-along "Passive Range-of-Motion Routine" intended to enhance the correctness and completeness of exercises performed, an "Active-Play" segment that pairs movements with songs, and a "Strengthening" section that targets muscle power. Goals of the DVD include (1) use of visual media to improve caregiver compliance and confidence, (2) improvement in arm function of patients with NBPP, and (3) promotion of exercise therapy in families with economic barriers or limited access to formal therapy.

\section{Home Exercise Program Compliance}

After receiving the DVD, the percentage of caregivers who performed a home exercise program increased significantly through time B. Caregiver compliance with home exercise was high even initially (74\%) when compared with other studies of children with motor disabilities $[9,10]$ and increased to $94 \%$ and $96 \%$, at times A and B, respectively. This high compliance rate in comparison with those in other published studies may be attributed to increased caregiver motivation to maintain or to begin a home exercise program after receiving the DVD. Other studies report that common barriers to physical therapy attendance include financial con- straints, insurance limitations, proximity of care facilities to patients' homes, and family schedules $[23,24]$, which suggests that therapists and physicians should consider alternative methods to increase therapy compliance in children with NBPP. Our study found that participation in a home exercise program may be enhanced by distribution of a DVD as an educational resource, which offers families a time-efficient, cost-effective way to incorporate home exercise into their daily routines.

\section{Use of Home Exercise Therapy Program DVD}

As a resource to guide home exercise, the DVD proved a popular alternative to the written handout. Use of the written handout decreased from an initial $42 \%$ to $29 \%$ at time A and remained at 19\% throughout the remainder of the study. In comparison, $69 \%$ of caregivers were using the DVD to guide home exercise at time A, decreasing to $57 \%$ for the remainder of the study. This is the first study to our knowledge to compare the use of written handouts to use of other education resources among children with NBPP. Results of other studies suggest that videotape modeling may more effectively encourage correctness of the exercises performed [20-22] and may generate, better than static illustrations, the confidence and motivation to complete exercises in a home environment [22]. A significant increase in caregivers who used memory to guide the exercise program also occurred after receiving the DVD, which has been shown to be an added benefit of video instruction in other conditions $[11,22]$.

\section{Impact on Caregiver Confidence}

DVD use resulted in a small but significant increase in caregiver confidence in the correctness of exercises performed [22], and additional strategies should be considered to augment this increase. For example, a recent home-based training program for arm and hand function in adults with hemi- 
plegic cerebral palsy found success by using weekly webcam interaction for feedback and communication between therapists and participants [25].

\section{Clinical Implications}

Clinicians often struggle to define the optimal time point for patient follow-up. Participation in home exercise dropped after time B, which suggests that caregivers may benefit from clinic follow-up 6-8 months after receiving the DVD. This face-to-face visit can offer an opportunity for therapists to answer questions from family members, provide positive feedback, and re-demonstrate exercises to reinforce behaviors [8]. Caregiver use of the DVD dropped significantly after time A, so compliance with home exercise may be encouraged by contacting families 3 months after the DVD is received and reminding them to use this resource [24].

\section{Arm Function Assessment}

Indicators of arm function were assessed concurrently with follow-up time points of the study to provide context of patient function while using the DVD. For children whose caregivers received the DVD, shoulder passive ROM did not significantly change, and shoulder active ROM increased significantly for shoulder abduction and external rotation in abduction (through time B). Biceps power increased significantly, from an average MRC grade 2 to grade 3 at follow-up, which indicates an acquired ability to perform antigravity movements. The lack of significant change in shoulder passive ROM may reflect the observation that these movements are historically difficult to improve [5], particularly external rotation in abduction and adduction, and, consequently, are closely monitored and targeted by therapists $[2,6]$. However, in the absence of exercise therapy or surgical treatment as indicated, the natural course of NBPP in children results in loss of muscle strength and a decline in ROM, possibly leading to contracture development and joint deformity $[1,6]$.

Although caregiver confidence increased after receiving the DVD, and some functional measures improved significantly for children who received the DVD, throughout the course of the study, no consistent statistically significant relationship between improved caregiver confidence and functional outcomes was found. At this time, we do not demonstrate or suggest any causal relationship between the content of the DVD and functional status.

\section{Study Limitations and Suggestions for Further Research}

Although our study population is large compared with similar studies of children with NBPP, our participants included caregivers of a limited number of children but covered a wide age range (Table 1). Consequently, important considerations include an inherent lack of confidence observed in caregivers of younger children and a potential variation in compliance relative to the age of the child [24]. Although the median Narakas score of children of caregivers surveyed at each time point remained constant at 2 , having children with more severe cases of NBPP may motivate caregivers to follow an exercise program more than caregivers with children with milder cases of NBPP [24].

Data were collected via self-reporting by caregivers, and researchers did not directly observe therapy attendance or verify home exercise adherence. The DVD was developed for use by patients at our institution, with exercises modeled from routines that our therapists regularly demonstrate. Distributing this DVD to patients not formally taught the featured exercises or seen at a facility with different exercise emphasis may have an impact on adherence to a home exercise program and the effectiveness of the DVD as a teaching tool $[8,20,24]$.

Additional investigation is needed to objectively assess the DVD's impact on correctness of exercises performed and to determine how frequently caregivers should be encouraged to review exercises after using the DVD; inaccurate memory of exercises poses a problem for persons of all ages $[19,26]$. Because this study was designed to assess the DVD as a resource currently given to all patients seen in our Brachial Plexus Program, outcomes were not compared with those in a control group of caregivers who did not receive the DVD. To truly establish the clinical value of the DVD content, future research should focus on comparing functional outcomes of children whose caregivers receive the DVD with outcomes in this control group and on addressing confounding variables such as quality of the DVD content and improvement of function with age. Further research to determine trends in home exercise compliance and functional outcomes within the general NBPP population to whom the DVD is not available would aid our evaluation of the DVD as an educational resource.

\section{CONCLUSIONS}

The "Home Exercise Therapy" DVD improved home exercise compliance when distributed to caregivers of children with NBPP, and increased caregiver confidence in the correctness of the exercises performed. Families appeared to prefer the video-based media format of the DVD over a written handout with static illustrations and increased use of memory to guide home exercise after receiving the DVD. Arm function in children was seen to improve concurrently. Our results suggest that this population may be receptive to alternative media and may benefit from dynamic modeling of exercises on video. To truly establish the clinical utility of the DVD, additional research is needed to compare functional outcomes, compliance, and correctness of exercises in the larger 
NBPP population, including individuals who have not received video-based exercise instruction during treatment.

\section{REFERENCES}

1. Waters PM. Update on management of pediatric brachial plexus palsy. J Pediatr Orthop B 2005;144:233-244.

2. Zafeiriou DI, Psychogiou K. Obstetrical brachial plexus palsy. Pediatr Neurol 2008;384:235-242.

3. Hoeksma AF, Wolf H, Oei SL. Obstetrical brachial plexus injuries: Incidence, natural course and shoulder contracture. Clin Rehabil 2000; 145:523-526.

4. Shenaq SM, Bullocks JM, Dhillon G, Lee RT, Laurent JP. Management of infant brachial plexus injuries. Clin Plast Surg 2005;321:79-98, ix.

5. Ramos LE, Zell JP. Rehabilitation program for children with brachial plexus and peripheral nerve injury. Semin Pediatr Neurol 2000;71:5257.

6. Price A, Tidwell M, Grossman JA. Improving shoulder and elbow function in children with Erb's palsy. Semin Pediatr Neurol 2000;71: 44-51.

7. Katz-Leurer M, Rotem H, Keren $\mathrm{O}$, Meyer S. The effects of a 'homebased' task-oriented exercise programme on motor and balance performance in children with spastic cerebral palsy and severe traumatic brain injury. Clin Rehabil 2009;238:714-724.

8. Taylor NF, Dodd KJ, McBurney H, Graham HK. Factors influencing adherence to a home-based strength-training programme for young people with cerebral palsy. Physiotherapy 2004:902:57-63.

9. Fragala-Pinkham MA, Haley SM, Rabin J, Kharasch VS. A fitness program for children with disabilities. Phys Ther 2005;8511:1182-1200.

10. Katz-Leurer M, Eisenstein E, Liebermann DG. Feasibility of motor capability training at home in children with acquired brain injury. Physiotherapy 2008;941:71-77.

11. Miller JS, Litva A, Gabbay M. Motivating patients with shoulder and back pain to self-care: Can a videotape of exercise support physiotherapy? Physiotherapy 2009;951:29-35

12. Boamah LM, Bohren JR, Pentiuk S, Baker R, Yi M, Moyer MS. Development and testing of a CD-ROM program for improving adolescent knowledge of inflammatory bowel disease. J Pediatr Gastroenterol Nutr 2010;505:521-525.
13. Golomb MR, McDonald $B C$, Warden SJ, et al. In-home virtual reality videogame telerehabilitation in adolescents with hemiplegic cerebral palsy. Arch Phys Med Rehabil 2010;911:1-8e1

14. Krouse HJ. Video modelling to educate patients. J Adv Nurs 2001;336: 748-757.

15. Moore J, Fiddler H, Seymour J, et al. Effect of a home exercise video programme in patients with chronic obstructive pulmonary disease. J Rehabil Med 2009;413:195-200.

16. Vestergaard S, Kronborg C, Puggaard L. Home-based video exercise intervention for community-dwelling frail older women: A randomized controlled trial. Aging Clin Exp Res 2008;205:479-486.

17. Janda M, Stanek C, Newman B, Obermair A, Trimmel M. Impact of videotaped information on frequency and confidence of breast selfexamination. Breast Cancer Res Treat 2002;731:37-43.

18. James, MA. Use of the Medical Research Council Muscle Strength Grading System in the upper extremity. J Hand Surg 2007;32:154-156.

19. Smith J, Lewis J, Prichard D. Physiotherapy exercise programmes: Are instructional exercise sheets effective? Physiother Theory Pract 2005; 212:93-102.

20. Friedrich $M$, Cermak $T$, Maderbacher $P$. The effect of brochure use versus therapist teaching on patients performing therapeutic exercise and on changes in impairment status. Phys Ther 1996;7610:10821088 .

21. Lin PC, Lin LC, Lin JJ. Comparing the effectiveness of different educational programs for patients with total knee arthroplasty. Orthop Nurs 1997;165:43-49.

22. Weeks DL, Brubaker J, Byrt J, Davis M, Hamann L, Reagan J. Videotape instruction versus illustrations for influencing quality of performance, motivation, and confidence to perform simple and complex exercises in healthy subjects. Physiother Theory Pract 2002;182:65-73.

23. Jack K, McLean SM, Moffett JK, Gardiner E. Barriers to treatment adherence in physiotherapy outpatient clinics: A systematic review. Man Ther 2010;153:220-228.

24. Sluijs EM, Kok GJ, van der Zee J. Correlates of exercise compliance in physical therapy. Phys Ther 1993;12:771-786.

25. Brown SH, Lewis CA, McCarthy JM, Doyle ST, Hurvitz EA. The effects of Internet-based home training on upper limb function in adults with cerebral palsy. Neurorehabil Neural Repair 2010;246:575-583.

26. Rastall M, Brooks B, Klarneta M, Moylan N, McCloud W, Tracey S. An investigation into younger and older adults' memory for physiotherapy exercises. Physiotherapy 1999;853:122-128.

\section{APPENDIX A. "Home Exercise Therapy Program for Brachial Plexus Palsy" DVD DVD HOME EXERCISE: 3, 6 and 12 MONTH PROGRAM SURVEY}

Code \#

Date:

This questionnaire is based on a follow-up after receiving the DVD of the brachial plexus home exercise program.

Please answer the following questions as best you can. Place a check mark next to the item that best answers the question:

1) How old is your child currently?

_ Newborn to 23 months old

- 24-36 months old

-3-6 years old

_ 6-18 years old 
2) Is your child currently in a weekly therapy program?

- yes

- no

If you answered yes, how often?

3) Are you continuing a home exercise program?

- yes

- no

4) If you answered yes to question 3, what are you using to guide the exercise program? (check all that apply):

_ written handout

_ memory

— video/DVD

_ attending a class what kind?

_ other (please specify)

5) How often is your child performing the exercises? Please place a check next to description of what your average is:

_ not at all

_ every diaper change (a daily average is 8 times)

_ 5-7 times daily

-3-4 times daily

_ 2 times daily

- 1 time daily

_ 4-5 times weekly

_ 2-3 times weekly

_ 1 time weekly

_ 2-3 times monthly

_ 1 time monthly

6) How long does the exercise session average when done?

_ less then 5 minutes

_ 5-10 minutes

- 11-20 minutes

_ 20-30 minutes

_ 30 or more minutes

7) Please rate how confident you feel that the exercises are being performed correctly. Place a mark $(X)$ along the scale below that best describes your confidence 